\title{
Analysis of $\mathrm{A}$ and $\mathrm{E}$ vitamer profiles in domestic raw and processed seafood consumed in Korea
}

\author{
Ye-Eun Park ${ }^{1}$, Yu-Jeong Gwak ${ }^{1}$, Jeong Kim ${ }^{1}$, YuSen Guan ${ }^{1}$, Won-Ho Hong ${ }^{1}$, Su-Jin Park ${ }^{1}$, \\ $\mathrm{Na}$-Young Yoon ${ }^{2}$, Yeon-Kye Kim², Sang Kuk Han ${ }^{3}$, Jiyeon Chun ${ }^{1,4 *}$ \\ ${ }^{1}$ Department of Food Science and Technology, Sunchon National University, Suncheon 57922, Korea \\ ${ }^{2}$ Food Safety and Processing Research Division, National Institute of Fisheries Science, Busan 46083, Korea \\ ${ }^{3}$ Department of Environment Engineering and Biotechnology, Mokpo National Maritime University, Mokpo 58645, Korea \\ ${ }^{4}$ Kimchi Science and Industrialization Institute, Sunchon National University, Suncheon 57922, Korea
}

\section{국내 소비 수산자원 및 가공품 중의 비타민 A 및 E vitamers 분석 및 검증

\author{
박예은 ${ }^{1} \cdot$ 곽유정 $^{1} \cdot$ 김정 $^{1} \cdot$ 관우삼 $^{1} \cdot$ 홍원호 $^{1} \cdot$ 박수진 $^{1} \cdot$ 윤나영 $^{2} \cdot$ 김연계 $^{2} \cdot$ 한상국 $^{3} \cdot$ 천지연 $^{1,4 *}$ \\ ${ }^{1}$ 순천대학교 식품공학과, ${ }^{2}$ 국립수산과학원 식품위생가공과, \\ 3국립목포해양대학교 환경생명공학과, ${ }^{4}$ 순천대학교 김치연구소
}

\begin{abstract}
Simple simultaneous alkaline extraction (saponification) coupled with HPLC was validated and applied for the analysis of ten vitamers of $A$ (retinol and $\beta$-carotene) and $\mathbf{E}(\alpha-, \beta-, \gamma$-, and $\delta$-tocopherols $(T)$ and corresponding tocotrienols (T3)) in seafood. Limits of detection for retinol, $\beta$-carotene and $\alpha$-T were $0.380 \mu \mathrm{g} / 100 \mathrm{~g}, 0.602 \mu \mathrm{g} / 100 \mathrm{~g}$ and $0.0002 \mathrm{mg} / 100 \mathrm{~g}$, respectively. Analysis precision was excellent for all vitamers (RSD: repeatability $<\mathbf{2 . 4 \%}$, reproducibility $<4.5 \%$ ). Recoveries of vitamers ranged from $92 \%$ to $110 \%$, showing good accuracy. Total vitamin $A$ and $E$ activities varied among seafood types, with ranges of 0.00-311.77 $\mu$ g retinol activity equivalent/100 $\mathrm{g}$ and 0.01-0.62 mg $\alpha$-tocopherol equivalent/100 $\mathrm{g}$, respectively. $\beta$-Carotene was found in some seafoods such as shellfish (ark shell, blue mussel and spiny top shell) and crustacean (gazami crab) samples as well as marine algae due to the presence of intestinal organ containing algae in edible parts. The highest $\beta$-carotene content $(689.84 \pm 29.86$ $\mu \mathrm{g} / 100 \mathrm{~g})$ was observed in seasoned oyster whereas the retinol content was highest in blackthroat seaperch (311.77 \pm 7.99 $\mu \mathrm{g} / 100 \mathrm{~g}$ ). $\alpha-\mathrm{T}$ was found in all samples and ranged from 0.07 to $4.72 \mathrm{mg} / 100 \mathrm{~g}$. This study provides reliable vitamin $A$ and $E$ profiles for domestic seafood in Korea.
\end{abstract}

Keywords : seafood, vitamin A, vitamin E, vitamers, method validation

서 론

비타민은 인체의 생리활성에 필수적인 미량 성분으로, 이 들의 화학적 및 생리학적 기능은 매우 다양하며 천연 식품에
광범위하게 분포되어 있다(Ball, 2005). 국내 미량비타민 섭 취는 식품뿐만 아니라 보충제와 같은 다양한 형태로도 섭취 되고 있으며, 이를 적정 수준으로 섭취하기 위해선 섭취하고 있는 식품과 제품들의 비타민 함량 수준을 알아보는 것이 필

*Corresponding author. E-mail : cjyfall@gmail.com, Phone : +82-62-750-3258, Fax : +82-61-750-3258

Received 13 October 2021; Revised 03 November 2021; Accepted 09 November 2021.

Copyright (c) The Korean Society of Food Preservation.

This is an Open Access article distributed under the terms of the Creative Commons Attribution Non-Commercial License (http://creativecommons.org/licenses/by-nc/4.0) which permits unrestricted non-commercial use, distribution, and reproduction in any medium, provided the original work is properly cited. 
요하다(Han 등, 2018). 한국영양학회와 보건복지부에서 발간 되는 한국인 영양소 섭취기준(KDRIs, 2020)은 미량 영양소의 과잉 섭취의 문제를 해결하기 위해 추정평균필요량(estimated average requirement, EAR), 권장섭취량(recommended nutrient intake, RNI), 충분섭취량(adequate intake, AI) 및 상한섭취 량(tolerable upper intake level, UL)을 각각의 영양소별로 제 공하고 있다. 지용성 비타민의 경우 과잉 섭취 시 체내에 축 적되어 독성을 야기할 수 있는 것으로 알려져 있어 각별한 주의가 필요하다(Bae 등, 2007; Hwang, 2002). 또한, 비타민 $\mathrm{D}$ 와 $\mathrm{K}$ 를 제외한 모든 비타민은 체내에서 적정량으로 합성되 지 않으므로 다양한 식품 또는 보충제를 통해 섭취해야 한다 (Shrivas 등, 2018).

비타민 $\mathrm{A}$ 는 동물성 식품에서 발견되는 레티놀과 채소 및 과일과 같은 식물성 식품에서 발견되는 카로티노이드의 형태 로 존재하고 있다(Tang 등, 2010). 600여 종의 카로티노이드 중 베타카로틴은 비타민 $\mathrm{A}$ 의 전구체로 작용하며, 체내에서 비타민 A의 활성을 나타낸다(Hwang 등, 2019). 비타민 A의 결핍은 안구건조증, 성장장애, 면역세포기능의 손상과 같은 질병을 발생시킬 수 있으며 특히 점막 면역의 심각한 손상을 발현시킬 수 있다(Semba, 2002; Sommer, 2008). 비타민 E는 포화 유도체인 4 개의 토코페롤 $(\alpha-, \beta-, \gamma$-, $\delta$-tocopherol)과 불 포화 유도체인 4 개의 토코트리에놀( $\alpha-, \beta-, \gamma-, \delta$-tocotrienol) 로 구성되어 있으며, 고지혈증 개선, 항산화 및 혈당 저하 등 다양한 생리활성을 나타낸다(Chun 등, 2013). 그러나, 결핍 시 말초 신경병증, 운동실조증 및 빈혈과 같은 질병을 일으킬 수 있으며, 연령대로는 어린이와 노인에서 결핍증상이 유발 될 수 있다(Dror과 Allen, 2011).

국내에서는 동물성 단백질 공급량의 $39 \%$ 를 차지하고 있 는 수산자원이 중요한 영양공급원 중 하나로 이용되오고 있 으며, 3 면이 바다로 둘러쌍인 한반도의 지형적 특성에 따라 오래전부터 다양한 종류의 수산물 섭취가 이루어지고 있다 (Lee와 Kim, 2003). 특히, 바다에서 서식하는 수산물에는 인 체에 필요한 여러 가지 영양성분, 특히 단백질과 무기질 공급 원으로 중요한 역할을 담당하고 있으며 이 외에도 다양한 기 능성 물질들을 함유하고 있다(Mok 등, 2007). 국내 수산자원 의 영양성분은 국립수산과학원에서 주기적으로 발간되고 있 는 표준수산물성분표(Composition Table of Marine Products in Korea)에서 영양성분에 대한 데이터를 제공하고 있으나, 제9개정판인 표준수산물성분표(2018)에 수록된 지용성 비타 민 항목으로 비타민 A(retinol)만 수록되어 있으며, 이 외의 지용성 비타민에 대한 데이터는 전무한 실정이다.

본 연구는 국내에서 다소비되는 다양한 수산물 및 수산가 공품을 선정하고 이들의 비타민 $\mathrm{A}$ 와 $\mathrm{E}$ 를 분석하였다. 또한, 국가데이터베이스로의 활용을 위하여 분석법 검증 및 분석품
질관리를 수행하여 분석법과 생산되는 데이터의 신뢰도를 확 보하고자 하였다.

\section{재료 및 방법}

\section{시약 및 시료준비}

비타민 $\mathrm{A}$ (retinol, $\beta$-carotene)와 비타민 $\mathrm{E}(\alpha-, \beta-, \gamma-, \delta$ tocopherol) 분석을 위한 표준품은 Sigma Aldrich Co.(St. Louis, MO, USA)에서 구입하여 사용하였다. 추출 및 분석에 사용된 시약과 용매는 특급 및 HPLC 등급을 사용하였다.

시료는 연근해, 내수면, 다소비 수산물 중 표준수산물성분 표(Composition Table of Marine Products in Korea, 2018)에 따라 어류, 패류, 두족류, 갑각류, 해조류, 수산가공품(건조품 및 염장품)으로 분류하고 분류군별 2종 이상의 수산자원을 샘플링하였다(Table 1). 선정된 총 20종의 시료는 비가식부 를 제거한 뒤 가식부위만을 균질화한 다음 소분하여 분석실 로 배송되었으며, 배송된 시료는 분석 전까지 $-70^{\circ} \mathrm{C}$ 에서 보관 하며 사용하였다.

\section{지용성 성분 추출(Saponification)}

시료 $5 \mathrm{~g}$ 을 유리 추출관에 취한 후 $6 \%$ pyrogallol in ethanol 용액을 $10 \mathrm{~mL}$ 첨가하여 잘 섞이도록 10 분 동안 sonication(8893-DHT, Cole-Parmer, Chicago, IL, USA) 하 였다. 다음으로 추출관에 $60 \% \mathrm{KOH}$ 용액을 $8 \mathrm{~mL}$ 넣어준 후 혼합하고, 추출관의 상부에 질소를 주입하여 공기를 치환시 켰다. 질소로 치환된 추출관에 air condenser를 부착한 후 shaking water bath(HB-205SW, Hanbaek Scientific Co., Bucheon, Korea)에서 $75^{\circ} \mathrm{C}, 100 \mathrm{rpm}, 1$ 시간 동안 반응시켜 검화(saponification)하였다. 반응이 끝난 추출관은 충분히 냉 각시킨 후 $2 \% \mathrm{NaCl} 20 \mathrm{~mL}$ 를 가하여 반응을 종결하였다. 검 화액에 추출용매(hexane:ethyl acetate $=85: 15, \mathrm{v} / \mathrm{v}, 0.01 \%$ 2,6-di-tert-butyl-4-methylphenol) $15 \mathrm{~mL}$ 를 가하여 2분간 혼 합 후 암실에서 정치시켜 지용성 성분이 추출된 hexane층을 분리하였다. 분리된 hexane층은 sodium sulfate anhydrous가 채워진 유리관에 통과시켜 추출액의 수분을 제거한 후 50 $\mathrm{mL}$ volumetric flask에 수집하였다. 이 과정은 총 3 회 반복하 였으며, 추출용매를 이용하여 수집된 추출액은 $50 \mathrm{~mL}$ 로 정 용하여 잘 혼합한 후 분석에 사용하였다.

\section{비타민 A 함량 분석(HPLC)}

비타민 A 분석은 Thomas 등(2001)의 방법에 따라 레티놀 과 베타카로틴을 동시분석하였다. Saponication 법으로 추출 한 추출액을 시험관에 $10 \mathrm{~mL}$ 취해 질소로 전량 휘발시킨 후 클로로포름과 에탄올 혼합용액 $(1: 4, \mathrm{v} / \mathrm{v})$ 을 $1 \mathrm{~mL}$ 가하여 재 
Table 1. Acquired region and purchase date of marine resources in Korea

\begin{tabular}{|c|c|c|c|c|}
\hline Classification & Common name & Scientific name & Acquired region & Purchase date \\
\hline \multirow{3}{*}{$\begin{array}{l}\text { Fish } \\
(n=4)\end{array}$} & Pacific herring & Clupea pallasii & Pohang & $19 / 05$ \\
\hline & Korean pomfret & Pampus argenteus & Jindo & $19 / 05$ \\
\hline & Blackthroat seaperch & Doederleinia berycoides & Jejudo & $19 / 11$ \\
\hline \multirow{2}{*}{$\begin{array}{l}\text { Crustacean } \\
(\mathrm{n}=3)\end{array}$} & Razor mud shrimp & Solenocera melantho & Busan & $19 / 06$ \\
\hline & Gazami crab & Portunus trituberculatus & Busan & $19 / 06$ \\
\hline \multirow{2}{*}{$\begin{array}{c}\text { Seaweed } \\
(\mathrm{n}=3)\end{array}$} & Seaweed fusiforme & Hizikia fusiforme & Wando, Yeosu, Sacheon & $19 / 03$ \\
\hline & Seersucker & Costaria costata & Wando & $19 / 02$ \\
\hline \multirow{3}{*}{$\begin{array}{l}\text { Cephalopod } \\
\qquad(n=3)\end{array}$} & Schoolmaster gonate squid & Berryteuthismagister & Donghae & $19 / 04$ \\
\hline & Common squid & Todarodes pacificus & \multirow{2}{*}{ Busan } & $19 / 09$ \\
\hline & Common octopus & Octopus vulgaris & & $21 / 03$ \\
\hline \multirow{3}{*}{$\begin{array}{c}\text { Shellfish } \\
(n=4)\end{array}$} & Ark shell & Scapharca broughtonii & \multirow{3}{*}{ Geojedo } & $19 / 06$ \\
\hline & Spiny top shell & Turbo cornutus & & $19 / 06$ \\
\hline & Blue mussel & Mytilus edulis & & $19 / 06$ \\
\hline \multirow{7}{*}{$\begin{array}{l}\text { Processed products } \\
\qquad(\mathrm{n}=7)\end{array}$} & Anchovy sauce & - & \multirow{7}{*}{ Market } & \multirow{7}{*}{$19 / 09$} \\
\hline & Dried codfish & - & & \\
\hline & Half-dried Herring & - & & \\
\hline & Salted mackerel & - & & \\
\hline & Salted oysters & - & & \\
\hline & Salted pollack roe & - & & \\
\hline & Sliced smoked salmon & - & & \\
\hline
\end{tabular}

용해한 후 $0.45 \mu \mathrm{m}$ membrane filter(Futecs Co., Daejeon, Korea)로 여과한 후 분석에 사용하였다. 분석에 사용된 HPLC는 Shimadzu(Kyoto, Japan), column은 Vydac 201TP $\mathrm{C}_{18}(4.6 \times 250 \mathrm{~mm}, 5 \mu \mathrm{m}$, GRACE, Santa Clara, CA, USA) 으로 사용하였다. 레티놀 및 베타카로틴 정량 분석을 위한 이 동상은 methanol, butanol 및 DDW(deionized distilled water) 혼합용액 $\mathrm{A}(89.5: 10: 0.5, \mathrm{v} / \mathrm{v} / \mathrm{v})$ 와 methanol, butanol 및 $\mathrm{DDW}$ 혼합용액 $\mathrm{B}(60: 10 ; 30, \mathrm{v} / \mathrm{v} / \mathrm{v})$ 를 사용하였으며, 분석 시 사용된 gradient 조건은 Table 2에 나타내었다. 분석 시 $\mathrm{PDA}($ photodiode array detector, Shimadzu)를 사용하여 각각 $325 \mathrm{~nm}$ 와 $452 \mathrm{~nm}$ 에서 검출하였으며, 이때 injection volume 은 $20 \mu \mathrm{L}$, flow rate는 $1 \mathrm{~mL} / \mathrm{min}$, column oven 온도는 $30^{\circ} \mathrm{C}$ 에서 분석을 진행하였다. 섭취 시 비타민 $\mathrm{A}$ 활성을 나타내는 단위인 retinol activity equivalent(RAE)는 다음 식을 사용하 여 계산하였다.

$1 \mu \mathrm{g} \mathrm{RAE}=\mu \mathrm{g}$ retinol $+1 / 12 \mu \mathrm{g} \beta$-carotene
Table 2. HPLC gradient conditions for retinol and $\beta$-carotene simultaneous analyses

\begin{tabular}{ccc}
\hline Time $(\mathrm{min})$ & $\mathrm{A}^{1)}(\%)$ & $\mathrm{B}^{2)}(\%)$ \\
\hline 0 & 75 & 25 \\
8 & 75 & 25 \\
50 & 10 & 90 \\
55 & 10 & 90 \\
57 & 75 & 25 \\
65 & 75 & 25
\end{tabular}

${ }^{1)}$ Mobile phase A: methanol:butanol:water=89.5:10:0.5 (v/v/v).

${ }^{2)}$ Mobile phase B: methanol:butanol:water $=60: 10: 30(\mathrm{v} / \mathrm{v} / \mathrm{v})$.

비타민 $\mathrm{E}$ 함량 분석(HPLC)

비타민 $\mathrm{E}$ 분석은 식품공전(KFDA, 2017)의 방법에 따라 분석하였다. 추출액 $2 \mathrm{~mL}$ 을 시험관에 취한 후 질소로 전량 
휘발시킨 후 hexane(J.T.baker, Easton, PA, USA) $1 \mathrm{~mL}$ 로 재 용해 하였다. 그 다음 $0.5 \mu \mathrm{m}$ membrane filter(Advantec, Tokyo, Japan)로 여과하여 분석에 사용하였다. 비타민 $\mathrm{E}$ 정 량 분석을 위해 사용한 HPLC는 Shimadzu(Kyoto, Japan), column은 LiChrospher Diol 100 $(250 \times 4$ mm, $5 \mu \mathrm{m}$, Merck, Darmstadt, Germany)을 사용하였다. 분석 시 $\mathrm{FLD}$ (fluorescence detector, Shimadzu)를 이용하여 Ex $\lambda=285 \mathrm{~nm}, \mathrm{Em} \lambda=325 \mathrm{~nm}$ 에서 비타민 $\mathrm{E} 8$ 종 $\operatorname{homolog}(\alpha, \beta, \gamma, \delta$-tocopherol(T), $\alpha, \beta$, $\gamma, \delta$-tocotrienol $\left(\mathrm{T}_{3}\right)$ 를 분리 검출하였다. 이동상은 $0.6 \%$ isopropanol을 함유한 hexane을 사용하여 isocratic 조건으로 분석하였고, 이때 분석시간은 50 분, injection volume은 $20 \mu \mathrm{L}$, flow rate는 $1 \mathrm{~mL} / \mathrm{min}$ 이었다. 비타민 $\mathrm{E}$ 체내 활성을 나타내 는 $\alpha$-tocopherol equivalent $(\alpha-\mathrm{TE})$ 는 다음 식을 이용하여 계 산하였다.

$$
\begin{aligned}
\alpha-\mathrm{TE}= & (\alpha-\mathrm{T} \times 1.0)+(\beta-\mathrm{T} \times 0.5)+(\gamma-\mathrm{T} \times 0.1)+(\delta-\mathrm{T} \\
& \times 0.01)+(\alpha-\mathrm{T} 3 \times 0.3)+(\beta-\mathrm{T} 3 \times 0.05)
\end{aligned}
$$

\section{비타민 $\mathrm{A}$ 와 $\mathrm{E}$ 분석법의 직선성 검증}

비타민 $\mathrm{A}$ 와 $\mathrm{E}$ 분석 유효성에 따른 분석법 검증은 $\mathrm{AOAC}$ (2002a; 202b)가 제시하고 있는 single laboratory guideline에 따라 수행하였다. 각 성분의 직선성은 각각의 표준용액을 단 계적으로 희석하여 각 농도에서 3회 반복하여 HPLC로 분석 하였다. 표준용액의 피크 면적과 농도를 변수로 검량선을 작 성한 후 나타나는 검량선의 상관계수 값 $\left(\mathrm{R}^{2}\right)$ 을 이용하여 직 선성의 유효성을 확인하였다.

\section{비타민 $\mathrm{A}$ 와 $\mathrm{E}$ 분석법의 검출한계(LOD) 및 정량한계(LOQ) 검증}

분석 검증을 위한 검출한계(limit of detection, LOD) 및 정량 한계(limit of quantification, LOQ)는 공시험액(blank)을 HPLC 로 분석하여 얻은 signal-to-noise $(\mathrm{S} / \mathrm{N})$ 의 평균값에 표준편차 를 각각 3 과 10 을 곱하여 나온 값을 더하여 산출하였다. $\mathrm{LOD}$ 이하의 값은 $\mathrm{ND}$ (not detected)로 표시하였다.

\section{비타민 $\mathrm{A}$ 와 $\mathrm{E}$ 분석법의 정밀성 및 정확성 검증}

분석법의 정밀성(precision)은 상업용 분유(Imperial dream XO world class 3, Namyang, Seoul, Korea)를 시료로 사용하 여 하루에 5 회 반복 실험한 결과와 5 일간 5 회 반복 실험한 결 과의 표준편차를 각각 repeatability(relative standard deviation, $\left.\mathrm{RSD}_{\mathrm{r}}\right)$ 와 reproducibility $\left(\mathrm{RSD}_{\mathrm{R}}\right)$ 로 나타내어 평가하였다. 정 확성(accuracy)은 NIST(National Institute of Standard and Technology, Gaithersburg, MD, USA)에서 구매한 표준참고 물질(standard reference material, SRM) SRM 1869(Infant/
Adult Nutritional Foemula II(milk/whey/soy based))을 사용 하였다. SRM 1869의 레티놀, 베타카로틴 및 비타민 E 함량 을 분석한 후 NIST에서 제시한 참고값(certified value)과 분 석값(analytical value)을 비교하여 회수율(recovery, \%)을 구 하여 분석법의 정확성을 평가하였다.

\section{분석품질관리}

본 연구가 수행되는 모든 기간 동안 품질관리시료인 상업 용 분유를 반복 분석하여 표준편차 $5 \%$ 이내에 포함되는 10 개의 데이터 값을 산출한 후 이들의 평균값을 품질관리도표 (quality control(QC) chart) 작성을 위한 기준값으로 선정하 였다. 품질관리도표의 관리상한선(upper control line, UCL) 과 관리하한선(lower control line, LCL), 조치상한선(upper action line, UAL) 및 조치하한선(lower action line, LAL)은 다음과 같이 기준을 설정하여 시료 분석 기간동안 분석품질 관리에 사용하였다.

$$
\begin{aligned}
& \mathrm{UCL} \text { and } \mathrm{LCL}=\text { mean } \pm(2 \times \text { standard deviation }) \\
& \mathrm{UAL} \text { and } \mathrm{LAL}=\text { mean } \pm(3 \times \text { standard deviation })
\end{aligned}
$$

\section{분석숙련도 시험}

분석 숙련도 평가를 위해 영국 식품환경연구청(Department for Environment, Food and Rural Afairs, DEFRA)에서 주관 하는 국제 분석숙련도시험(analysis proficiency test) Food Analysis Performance Assessment Scheme(FAPAS)에 참여 하여 결과를 비교 평가하였다. 이때 제공된 분석시험 시료는 powdered baby food였으며, 레티놀과 $\alpha$-토코페롤 지표 성분 을 본 연구에서 검증된 분석법을 이용하여 분석하고 전 세계 에서 참가한 실험실의 분석 결과와 함께 z-score를 비교하여 숙련도를 평가하였다.

\section{결과 및 고찰}

분석법의 직선성, 검출한계(LOD) 및 정량한계(LOQ) 검증

본 연구에서 비타민 $\mathrm{A}$ 와 $\mathrm{E}$ 분석에 관한 직선성, 검출한계 및 정량한계는 Table 3에 나타내었다. 직선성은 각 표준품을 5-7개의 농도 수준으로 제조하여 각각 3회에 걸쳐 분석한 결 과, 모든 직선성의 상관계수 $\left(\mathrm{R}^{2}\right)$ 는 0.999 이상의 상관계수를 나타내어 본 연구에서 사용된 분석법의 직선성이 우수한 것 을 확인하였다.

PDA detector를 사용하여 분석한 레티놀과 베타카로틴의 $\mathrm{LOD}$ 는 각각 $0.380 \mu \mathrm{g} / 100 \mathrm{~g}, 0.602 \mu \mathrm{g} / 100 \mathrm{~g}, \mathrm{LOQ}$ 는 각각 $0.996 \mu \mathrm{g} / 100 \mathrm{~g}, 1.402 \mu \mathrm{g} / 100 \mathrm{~g}$ 을 나타냈다. Domínguez 등 (2017)은 HPLC-PDA를 사용하여 레티놀을 분석하였으며, 
Table 3. Linearity of retinol, $\beta$-carotene and tocopherols analyses

\begin{tabular}{|c|c|c|c|c|}
\hline Analytes & Linear equation $(y=a x+b)$ & Correlation of linearity $\left(\mathrm{R}^{2}\right)$ & $\mathrm{LOD}^{1)}$ & $\mathrm{LOQ}^{2)}$ \\
\hline Retinol $(\mu \mathrm{g} / 100 \mathrm{~g})$ & $y=95,272 x-1,943.1$ & 1.000 & 0.380 & 0.996 \\
\hline$\beta$-Carotene $(\mu \mathrm{g} / 100 \mathrm{~g})$ & $y=46,919 x-1,519.7$ & 1.000 & 0.602 & 1.402 \\
\hline$\alpha$-Tocopherol (mg/100 g) & $\mathrm{y}=1,891,611.3 \mathrm{x}-86,100.8$ & 0.999 & 0.0002 & 0.0006 \\
\hline$\beta$-Tocopherol (mg/100 g) & $y=1,722,982.4+3,950.4$ & 1.000 & 0.0001 & 0.0003 \\
\hline$\gamma$-Tocopherol (mg/100 g) & $\mathrm{y}=2,177,608.9+74,121.9$ & 1.000 & 0.0001 & 0.0003 \\
\hline$\delta$-Tocopherol $(\mathrm{mg} / 100 \mathrm{~g})$ & $\mathrm{y}=2,015,335.0-70,800.6$ & 0.999 & 0.0001 & 0.0002 \\
\hline
\end{tabular}

${ }^{1)}$ Limit of detection.

${ }^{2)}$ Limit of quantification.

이때의 LOD와 LOQ는 각각 $0.94 \mu \mathrm{g} / 100 \mathrm{~g}$ 과 $2.93 \mu \mathrm{g} / 100$ $\mathrm{g}$ 이라고 보고하였다. UV detector를 사용하여 베타카로틴을 분석한 Karnjanawipagul 등(2010)은 분석법의 LOD와 LOQ 는 각각 $4 \mu \mathrm{g} / 100 \mathrm{~g}$ 과 $11 \mu \mathrm{g} / 100 \mathrm{~g}$ 이라 보고하였다. 이에 비 하여 본 연구에서 사용된 분석법의 $\mathrm{LOD}$ 와 $\mathrm{LOQ}$ 는 약 2.5-20 배 정도 낮은 것으로 나타나 수산 자원 및 식품 중 미량 함유 하고 있는 레티놀과 베타카로틴을 낮은 수준까지 분석이 가 능할 것으로 보인다. 한편, 비타민 $\mathrm{E}$ homolog 분석은 $\mathrm{FLD}$ 를 사용하여 분석하였으며 $\mathrm{LOD}$ 는 $\alpha-, \beta-, \gamma-, \delta$-T가 각각 0.0002 $\mathrm{mg} / 100 \mathrm{~g}, 0.0001 \mathrm{mg} / 100 \mathrm{~g}, 0.0001 \mathrm{mg} / 100 \mathrm{~g}, 0.0001 \mathrm{mg} / 100$ $\mathrm{g}, \mathrm{LOQ}$ 는 각각 $0.0006 \mathrm{mg} / 100 \mathrm{~g}, 0.0003 \mathrm{mg} / 100 \mathrm{~g}, 0.0003$ $\mathrm{mg} / 100 \mathrm{~g}, 0.0002 \mathrm{mg} / 100 \mathrm{~g}$ 으로 나타났다. HPLC-FLD로 분 석한 Gornas 등(2014)은 비타민 E 각 성분의 $\mathrm{LOD}$ 는 0.0002$0.0005 \mu \mathrm{g}$, LOQ는 0.0006-0.0016 $\mu \mathrm{g}$ 이라 보고하였는데, 이 에 비하여 본 연구에서 적용한 비타민 $\mathrm{E}$ 분석법이 $\mathrm{LOD}$ 와 $\mathrm{LOQ}$ 가 약 10 배 정도 낮은 것으로 나타나 미량 존재하는 비
타민 $\mathrm{E}$ 의 정량적 분석에 유용할 것으로 사료된다.

\section{분석법의 정밀성 및 정확성 검증}

비타민 $\mathrm{A}$ 와 $\mathrm{E}$ 분석법의 정밀성은 Table 4 에 나타내었다. $\mathrm{AOAC}$ 의 단일실험실 분석법 검증 가이드라인(2002)에 따르 면 시료 농도 수준이 $1 \mathrm{mg} / 100 \mathrm{~g}$ 일 때 정밀성의 반복성과 재 현성의 수용 범위는 각각 $6 \%, 11 \%$ 이하 수준이며, $1 \mu \mathrm{g} / 100$ $\mathrm{g}$ 의 수용범위는 각각 $8 \%, 16 \%$ 이하로 수용 가능한 범위를 더 넓게 나타내고 있다. 본 연구에서 비타민 A와 $\mathrm{E}$ 에 대한 정밀성 검증 결과 모든 성분에서 반복성의 상대표준편차 $\mathrm{RSD}_{\mathrm{r}}$ 은 $0.4-2.4 \%$, 재현성의 상대표준편차 $\mathrm{RSD}_{\mathrm{R}}$ 은 $1.7-4.5 \%$ 를 나타냈다. 이것은 $\mathrm{AOAC}$ 에서 제시한 단일실험실에서 확 보해야 할 정밀성 기준범위보다 낮은 수준으로 본 연구에서 적용한 분석법이 수용 가능한 범위를 충족시킴을 확인할 수 있었다. 표준참고물질 SRM 1869 를 분석하여 측정한 회수율 은 모든 성분에서 92.2-110.4\%의 범위를 나타내어 본 연구에

Table 4. Precision of retinol, $\beta$-carotene and tocopherols analyses

\begin{tabular}{|c|c|c|c|c|}
\hline \multirow{2}{*}{ Analytes } & \multicolumn{2}{|c|}{ Repeatability ${ }^{1)}$} & \multicolumn{2}{|c|}{ Reproducibility $^{2)}$} \\
\hline & Mean $\pm \mathrm{SD}^{3)}$ & $\operatorname{RSDr}^{4)}(\%)$ & Mean \pm SD & $\mathrm{RSD}_{\mathrm{R}}^{5)}(\%)$ \\
\hline Retinol ( $\mu \mathrm{g} / 100 \mathrm{~g})$ & $536.60 \pm 9.68$ & 1.8 & $541.08 \pm 14.73$ & 2.7 \\
\hline$\beta$-Carotene $(\mu \mathrm{g} / 100 \mathrm{~g})$ & $123.26 \pm 3.01$ & 2.4 & $125.23 \pm 5.65$ & 4.5 \\
\hline$\alpha$-Tocopherol (mg/100 g) & $8.70 \pm 0.07$ & 0.7 & $8.90 \pm 0.15$ & 1.7 \\
\hline$\beta$-Tocopherol (mg/100 g) & $0.40 \pm 0.00$ & 0.4 & $0.42 \pm 0.02$ & 4.2 \\
\hline$\gamma$-Tocopherol (mg/100 g) & $7.79 \pm 0.07$ & 0.8 & $7.93 \pm 0.24$ & 3.0 \\
\hline$\delta$-Tocopherol (mg/100 g) & $2.38 \pm 0.04$ & 1.6 & $2.44 \pm 0.10$ & 4.2 \\
\hline
\end{tabular}

${ }^{1)}$ Repeatability refers to the results of independent 5 determinations in triplicates obtained by analyzing a sample five times on the same day. ${ }^{2}$ Reproducibility refers to the results of independent 5 determinations in triplicates obtained by analyzing a sample five times on different days. ${ }^{3)}$ Standard deviation.

${ }^{4)} \mathrm{RSDr}$, Relative standard deviation for repeatability.

${ }^{5)} \mathrm{RSD}_{\mathrm{R}}$, Relative standard deviation for reproducibility. 
서 적용한 분석법의 정확성이 우수함을 확인할 수 있었다 (Table 5). AOAC guideline은 시료 농도 수준에 따라 회수율 이 달라지므로 수용가능한 회수율 범위를 농도에 따라 1 $\mathrm{mg} / 100 \mathrm{~g}$ 일 경우 $80-115 \%, 1 \mu \mathrm{g} / 100 \mathrm{~g}$ 일 경우 $70-125 \%$ 로 제시하고 있다. 비타민 $\mathrm{A}$ 와 $\mathrm{E}$ 의 분석법의 경우 수용범위 안 에 충족되는 회수율(92.2-110.4\%)을 확보하여 본 연구에서 분석한 모든 성분에 대한 정량 분석법의 정확성이 우수함을 확인할 수 있다.

\section{수산물 및 수산 가공품의 비타민 $A$ 함량}

수산물 및 수산 가공품에 대한 레티놀 및 베타카로틴 함량 은 Table 6 과 같이 수산물의 군별 및 종류에 따라 넓은 차이를 나타냈다. 레티놀 함량은 어류에 속하는 눈볼대(blackthroat seaperch)에서 $311.77 \mu \mathrm{g} / 100 \mathrm{~g}$ 으로 가장 높은 함량을 나타 냈다. 베타카로틴은 가공품 중 어리굴젓(seasoned fermented oyster)이 가장 높은 함량 $(613.10 \pm 5.18 \mu \mathrm{g} / 100 \mathrm{~g})$ 을 보였으며 다음으로 톳(fusiformis)에서 높은 함량(440.99 $\pm 18.85 \mu \mathrm{g} / 100$ g)을 나타냈다. 한편, 수산 시료 20종 중 청어(pacific herring), 대롱수염새우(razor mud shrimp), 갈고리흰오징어(schoolmaster gonate squid), 멸치액젓(anchovy sauce), 바다대구포(dried codfish), 자반고등어(salted mackerel)에서는 레티놀과 베타 카로틴 모두 검출되지 않았다. 베타카로틴의 경우 주로 식물 성 식품에 존재하는데 본 연구에서 분석된 20 종 중에서는 동 물성 수산자원인 패류와 갑각류에서도 베타카로틴 함량이 상 당량 검출되었다. 이는 이들이 해조류와 같은 식물성 수산물 을 먹이로 이용하며 생육하고 있어 내장에 베타카로틴 함량 이 높은 다시마와 미역과 같은 분해물들이 잔류되어 있는데, 패류와 갑각류와 같은 동물성 수산자원은 주로 내장을 포함 하여 가식부로 이용되기 때문에 동물성 자원이지만 식물성에
서 존재하는 베타카로틴의 함량이 27.17-335.05 $\mu \mathrm{g} / 100 \mathrm{~g}$ 수 준으로 함유될 수 있는 것으로 보여진다. 한편, 동물성 자원 인 어리굴젓의 경우는 굴 내장에 존재하는 다시마나 미역과 같은 해조류의 잔물이 존재하는 것 외에도 가공 시 조미료로 사용되는 고춧가루로 인하여 베타카로틴 함량이 가장 높게 나타나는 원인으로 사료된다. 명란젓(seasoned pollack roe) 의 경우도 가공 시 조미료로 첨가되는 고춧가루에 의해 베타 카로틴 함량이 검출되는 것으로 보여진다. 반면, 두족류와 어 류와 같이 내장을 불가식부로 제거하는 수산자원의 경우, 식 물성 베타카로틴이 검출되지 않고 동물성 레티놀 성분만 일 부 검출되었다. Moon 등(2019)은 수산물을 사용하여 조리한 해물콩나물찜과 코다리찜에선 레티놀이 검출되지 않았으나, 일부 해산물 식단에선 다량의 레티놀이 검출되었다고 보고하 였으며, Park 등(2018)도 수산물이 들어간 식단에서 일부 식 단의 경우 레티놀이 검출되지 않았다고 보고하여 수산자원의 종류에 따라 비타민 A 함량에 차이를 보이는 것을 알 수 있다.

수산자원의 레티놀과 베타카로틴의 함량을 함께 고려한 총 비타민 A activity(retinol activity equivalent, RAE)는 Table 6과 같다. 레티놀 함량이 절대적으로 높았던 눈볼대 $(311.77 \mu \mathrm{g} \mathrm{RAE} / 100 \mathrm{~g}$ )가 가장 높은 값을 보였으며 다음으 로 베타카로틴 함량이 높은 어리굴젓(74.96 $\mu \mathrm{g} \mathrm{RAE} / 100 \mathrm{~g})$, 진주담치(blue mussel, $37.25 \mu \mathrm{g} \mathrm{RAE} / 100 \mathrm{~g}$ ) 그리고 톳 (36.75 $\mu \mathrm{g} \mathrm{RAE} / 100 \mathrm{~g})$ 순으로 높게 나타났다. 한국 성인 기준 비타민 A 권장섭취량은 여성은 $650 \mu \mathrm{g} \mathrm{RAE,} \mathrm{남성은} 800 \mu \mathrm{g}$ $\mathrm{RAE}$ 이다(KDRIs, 2020). 수산자원은 한국인의 식단에서 자주 섭취되는 자원으로 이를 통해 필요한 비타민 $\mathrm{A}$ 섭취량을 상 당량 채울 수 있을 것으로 보여지며, 특히 눈볼대와 같은 수산 식품의 경우 $100 \mathrm{~g}$ 의 섭취로 여성은 약 $48 \%$, 남성은 약 $38 \%$ 의 일일권장섭취량을 충족시킬 수 있을 것으로 보여진다.

Table 5. Accuracy of retinol, $\beta$-carotene and tocopherols analyses

\begin{tabular}{|c|c|c|c|c|}
\hline \multirow{2}{*}{$\mathrm{SRM}^{1)}$} & \multirow{2}{*}{ Analytes } & \multicolumn{2}{|c|}{ Accuracy } & \multirow{2}{*}{ Recovery $^{4)}(\%)$} \\
\hline & & Certified value ${ }^{2)}$ & Analytical value ${ }^{3)}$ & \\
\hline \multirow{6}{*}{ SRM 1869} & Retinol $(\mu \mathrm{g} / 100 \mathrm{~g})$ & $1,927.0 \pm 32.0$ & $1,945.89 \pm 12.03$ & 101.0 \\
\hline & $\beta$-Carotene $(\mu \mathrm{g} / 100 \mathrm{~g})$ & $105.0 \pm 26.0$ & $96.79 \pm 2.80$ & 92.2 \\
\hline & $\alpha$-Tocopherol (mg/100 g) & $21.72 \pm 0.62$ & $21.80 \pm 0.12$ & 100.4 \\
\hline & $\beta$-Tocopherol (mg/100 g) & $0.42 \pm 0.07$ & $0.47 \pm 0.02$ & 110.4 \\
\hline & $\gamma$-Tocopherol (mg/100 g) & $9.94 \pm 0.51$ & $10.19 \pm 0.00$ & 102.5 \\
\hline & $\delta$-Tocopherol (mg/100 g) & $3.25 \pm 0.29$ & $3.01 \pm 0.07$ & 92.7 \\
\hline
\end{tabular}

\footnotetext{
${ }^{1)}$ SRM, standard reference material; SRM 1869, Infant/Adult Nutritional Formula II(milk/whey/soy based).

${ }^{2)}$ The certified value for the contents of corresponding analytes in SRM provided by NIST.

${ }^{3)}$ The analytical value obtained in this study.

${ }^{4}$ Recovery $(\%)=$ analytical value $/$ certified value $\times 100$.
} 
Table 6. The contents of retinol and $\beta$-carotene in marine resources and products

\begin{tabular}{|c|c|c|c|c|}
\hline \multirow[b]{2}{*}{ Classification } & \multirow[b]{2}{*}{ Sample name } & \multicolumn{3}{|c|}{ Vitamin A } \\
\hline & & $\begin{array}{l}\text { Retinol } \\
(\mu \mathrm{g} / 100 \mathrm{~g})\end{array}$ & $\begin{array}{l}\beta \text {-Carotene } \\
(\mu \mathrm{g} / 100 \mathrm{~g})\end{array}$ & $\begin{array}{c}\mathrm{RAE}^{1)} \\
(\mu \mathrm{g} / 100 \mathrm{~g})\end{array}$ \\
\hline \multirow{3}{*}{ Fish } & Blackthroat seaperch & $311.77 \pm 7.99$ & ND & 311.77 \\
\hline & Korean pomfret & $5.54 \pm 0.47$ & ND & 5.54 \\
\hline & Pacific herring & ND & ND & - \\
\hline \multirow{2}{*}{ Crustacean } & Razor mud shrimp & ND & ND & - \\
\hline & Gazami crab & ND & $135.40 \pm 7.16$ & 11.28 \\
\hline \multirow{2}{*}{ Marine algae } & Fusiformis & ND & $440.99 \pm 18.85$ & 36.75 \\
\hline & Seersucker & ND & $345.20 \pm 14.82$ & 28.77 \\
\hline \multirow{3}{*}{ Cephalopod } & Common squid & $9.77 \pm 0.78$ & ND & 9.77 \\
\hline & Schoolmaster gonate squid & ND & ND & - \\
\hline & Common octopus & $5.67 \pm 0.64$ & ND & 5.67 \\
\hline \multirow{3}{*}{ Shellfish } & Ark shell & $23.70 \pm 1.84$ & $27.17 \pm 2.85$ & 25.96 \\
\hline & Blue mussel & $34.81 \pm 0.99$ & $29.30 \pm 2.01$ & 37.25 \\
\hline & Spiny top shell & ND & $335.05 \pm 22.16$ & 27.92 \\
\hline \multirow{7}{*}{$\begin{array}{l}\text { Processed } \\
\text { products }\end{array}$} & Anchovy sauce & ND & ND & - \\
\hline & Dried codfish & ND & ND & - \\
\hline & Half-dried Herring & $2.79 \pm 0.15$ & ND & 2.79 \\
\hline & Salted mackerel & ND & ND & - \\
\hline & Seasoned oyster & $23.87 \pm 0.64$ & $613.10 \pm 5.18$ & 74.96 \\
\hline & Seasoned pollack roe & $32.42 \pm 0.58$ & $13.36 \pm 1.72$ & 33.53 \\
\hline & Sliced smoked salmon & $2.89 \pm 0.25$ & ND & 2.89 \\
\hline
\end{tabular}

${ }^{1)}$ Vitamin A activity is expressed as $\mu \mathrm{g}$ RAE (retinol activity equivalent) $/ 100$ g. $1 \mu \mathrm{g}$ RAE $=\mu \mathrm{g}$ retinol $+1 / 12 \mu \mathrm{g} \beta$-carotene.

\section{수산물 및 수산 가공품의 비타민 E 함량}

수산물 및 수산가공품에 대한 비타민 $\mathrm{E}$ 의 8종 vitamers 함 량 분석 결과와 비타민 $\mathrm{E}$ activity를 $\alpha$-tocopherol equivalent $(\alpha-\mathrm{TE})$ 로 Table 7 에 나타내었다. 본 연구에서 분석한 총 20종 수산식품에서 $\alpha$-T가 모두 검출되었으나, $\delta-\mathrm{T}_{3}$ 는 모든 시료에 서 검출되지 않았다. 수산식품의 $\alpha-\mathrm{T}$ 함량은 $0.07-4.72 \mathrm{mg} / 100$ $\mathrm{g}$ 의 분포를 나타냈으며, 명란젓이 $4.72 \mathrm{mg} / 100 \mathrm{~g}$ 으로 가장 높았고, 쇠미역이 $0.07 \mathrm{mg} / 100 \mathrm{~g}$ 으로 가장 낮은 것으로 나타 냈다. $\mathrm{Kim}$ 등(2021)은 해조류의 비타민 $\mathrm{E}$ 분석 시 $\alpha$-T를 제 외한 나머지 유도체들은 검출되지 않았다고 하였으나, 본 연 구에서 분석한 2 종의 해조류인 톳과 쇠미역에서는 $\alpha-T$ 와 $\beta-T$ 가 검출되었으며, 톳에서는 $\gamma$-T도 검출되었다. 이는 종의 차 이 외에도 수산자원의 서식지, 계절 등 다양한 생육환경에 따 라 검출되는 vitamers의 종류와 함량이 달라질 수 있기 때문
인 것으로 보여진다.

Table 7에 제시된 $\alpha$-TE는 체내 비타민 $\mathrm{E}$ 활성을 나타내며, $\gamma-\mathrm{T}_{3}$ 와 $\delta-\mathrm{T}_{3}$ 를 제외한 비타민 $\mathrm{E}$ 유도체들의 체내 활성도를 고려하여 산출되었으며 수산식품 20종은 0.01-0.62의 mg $\alpha$ $\mathrm{TE} / 100 \mathrm{~g}$ 의 범위를 나타냈다. 가공품 중에서는 명란젓 $(0.62$ $\mathrm{mg} \alpha$-TE/100 g), 훈제연어(0.52 mg $\alpha$-TE/100 g, 어리굴젓 $(0.35 \mathrm{mg} \alpha-\mathrm{TE} / 100 \mathrm{~g})$, 청어과메기(salted dried mackerel, $0.23 \mathrm{mg} \alpha-\mathrm{TE} / 100 \mathrm{~g})$ 순으로 높은 $\alpha$-TE 값을 보였으며, 비가 공품 중에서는 눈볼대( $0.29 \mathrm{mg} \alpha$-TE/100 g), 피조개(ark shell, $0.23 \mathrm{mg} \alpha$-TE/100 g), 대롱수염새우(razor mud shrimp, 0.22 $\operatorname{mg~} \alpha-\mathrm{TE} / 100 \mathrm{~g})$ 의 순으로 $\alpha$-TE 함량이 높게 나타났다. 가공 품 중 어리굴젓과 명란젓의 비교적 높은 $\alpha$-TE 값은 가공 시 첨가되는 고춧가루에 의한 비타민 $\mathrm{E}$ 함량의 추가적인 증가 때문인 것으로 보여진다. Kim 등(2006)은 지용성 비타민은 
Table 7. The contents of tocopherols and tocotrienols in marine resources and products

\begin{tabular}{|c|c|c|c|c|c|c|c|c|c|c|}
\hline \multirow{2}{*}{ Classification } & \multirow{2}{*}{ Sample name } & \multicolumn{9}{|c|}{ Tocopherol and tocotrienol contents (mg/100 g) } \\
\hline & & $\alpha-T^{1)}$ & $\beta-\mathrm{T}$ & $\gamma-\mathrm{T}$ & $\delta-\mathrm{T}$ & $\alpha-T_{3}^{2)}$ & $\beta-\mathrm{T}_{3}$ & $\gamma-\mathrm{T}_{3}$ & $\delta-\mathrm{T}_{3}$ & $\alpha-\mathrm{TE}^{3)}$ \\
\hline \multirow{3}{*}{ Fish } & Blackthroat seaperch & $2.00 \pm 0.09$ & $0.17 \pm 0.01$ & $0.01 \pm 0.00$ & $\mathrm{ND}^{4)}$ & ND & ND & ND & ND & 0.29 \\
\hline & Korean pomfret & $0.31 \pm 0.00$ & $0.10 \pm 0.00$ & $0.01 \pm 0.00$ & ND & $0.02 \pm 0.00$ & ND & $0.05 \pm 0.00$ & ND & 0.09 \\
\hline & Pacific herring & $0.14 \pm 0.00$ & $0.05 \pm 0.00$ & $0.01 \pm 0.00$ & ND & $0.01 \pm 0.00$ & ND & $0.00 \pm 0.00$ & ND & 0.04 \\
\hline \multirow{2}{*}{ Crustacean } & Razor mud shrimp & $1.71 \pm 0.07$ & $0.02 \pm 0.00$ & ND & ND & ND & ND & ND & ND & 0.22 \\
\hline & Gazami crab & $1.97 \pm 0.03$ & $0.05 \pm 0.00$ & $0.03 \pm 0.00$ & ND & ND & ND & $0.02 \pm 0.00$ & ND & 0.18 \\
\hline \multirow{2}{*}{$\begin{array}{l}\text { Marine } \\
\text { algae }\end{array}$} & Fusiformis & $0.71 \pm 0.02$ & $0.17 \pm 0.00$ & $0.05 \pm 0.00$ & ND & ND & ND & ND & ND & 0.16 \\
\hline & Seersucker & $0.07 \pm 0.00$ & $0.01 \pm 0.00$ & ND & ND & ND & ND & ND & ND & 0.01 \\
\hline \multirow{3}{*}{ Cephalopod } & Common squid & $1.05 \pm 0.01$ & $0.04 \pm 0.00$ & $0.03 \pm 0.00$ & $0.01 \pm 0.00$ & ND & ND & ND & ND & 0.13 \\
\hline & Schoolmaster gonate squid & $1.60 \pm 0.04$ & $0.03 \pm 0.00$ & ND & ND & ND & ND & ND & ND & 0.17 \\
\hline & Common octopus & $1.33 \pm 0.01$ & ND & ND & ND & $0.01 \pm 0.00$ & ND & ND & ND & 0.13 \\
\hline \multirow{3}{*}{ Shellfish } & Ark shell & $1.34 \pm 0.04$ & $0.20 \pm 0.01$ & ND & $\mathrm{ND}$ & ND & ND & ND & ND & 0.23 \\
\hline & Blue mussel & $0.68 \pm 0.02$ & $0.47 \pm 0.01$ & $0.06 \pm 0.00$ & $\mathrm{ND}$ & & ND & ND & ND & 0.16 \\
\hline & Spiny top shell & $0.37 \pm 0.02$ & $0.18 \pm 0.01$ & ND & ND & ND & ND & ND & ND & 0.13 \\
\hline \multirow{7}{*}{$\begin{array}{l}\text { Processed } \\
\text { products }\end{array}$} & Anchovy sauce & $0.66 \pm 0.02$ & ND & $0.02 \pm 0.00$ & ND & $0.03 \pm 0.00$ & ND & $0.19 \pm 0.00$ & ND & 0.08 \\
\hline & Dried codfish & $0.55 \pm 0.02$ & $0.12 \pm 0.00$ & $0.17 \pm 0.00$ & ND & ND & ND & ND & ND & 0.13 \\
\hline & Half-dried Herring & $0.60 \pm 0.01$ & $0.07 \pm 0.00$ & ND & ND & ND & ND & ND & ND & 0.09 \\
\hline & Salted mackerel & $2.15 \pm 0.06$ & $\mathrm{ND}$ & $0.19 \pm 0.01$ & ND & ND & ND & ND & ND & 0.23 \\
\hline & Seasoned oyster & $2.16 \pm 0.13$ & $0.24 \pm 0.01$ & $0.17 \pm 0.01$ & ND & ND & ND & ND & ND & 0.35 \\
\hline & Seasoned pollack roe & $4.72 \pm 0.08$ & $0.28 \pm 0.02$ & $0.04 \pm 0.00$ & ND & ND & ND & ND & ND & 0.62 \\
\hline & Sliced smoked salmon & $1.89 \pm 0.02$ & $0.25 \pm 0.01$ & $0.48 \pm 0.02$ & ND & $0.53 \pm 0.01$ & $0.03 \pm 0.00$ & ND & ND & 0.52 \\
\hline
\end{tabular}

${ }^{1)} \mathrm{T}$, tocopherol.

${ }^{2)} \mathrm{T} 3$, tocotrienol.

${ }^{3)} \mathrm{TE}$, Vitamin $\mathrm{E}$ activity is expressed as mg $\alpha$-tocopherol equivalent $(\alpha$-TE $) / 100$ g. $\alpha$-TE $=(\alpha-\mathrm{T} \times 1.0)+(\beta-\mathrm{T} \times 0.5)+(\gamma-\mathrm{T} \times 0.1)+(\delta$-T $\times$ $0.01)+\left(\alpha-T_{3} \times 0.3\right)+\left(\beta-T_{3} \times 0.05\right)$.

${ }^{4)}$ Not detected.

수분에 민감하여 손실 속도가 빨라진다고 보고하였고, $\mathrm{Kim}$ 등(2021)은 해조류의 생것과 건조품을 비교하였을 때 생것에 선 검출되지 않았으나 건조품에선 $\alpha-\mathrm{T}$ 가 검출되었다고 보고 하였다. 일반적으로 수산물 생것을 건조하거나 젓갈류와 같 이 양념을 첨가하여 수분활성도를 낮추는 경우 존재했던 영 양성분의 함량이 상대적으로 높아질 수 있으나 비타민 E와 같이 항산화능이 있는 경우 저장 및 가공 중 산화에 노출 시 그 함량이 감소될 수 있다. 본 연구에서 분석된 청어는 0.04 $\mathrm{mg} \alpha-\mathrm{TE} / 100 \mathrm{~g}$, 상당 기간 건조시켜 제조되는 수산가공품인 청어과메기는 $0.09 \mathrm{mg} \alpha-\mathrm{TE} / 100 \mathrm{~g}$ 을 보여주었다. 국가표준 식품성분표 기준에 따르면 생것 청어의 수분함량은 $66 \%$, 말 린 것은 24\%로(National Standard Composition Table, 2021)
건조에 의한 수분 제거로 고형분 함량이 약 두 배 이상 증가 하는 것을 보여주며 이로 인해 비타민과 같은 영양성분도 중 량 당 두 배 이상 증가될 것으로 생각되며, 이 중 일부 비타민 $\mathrm{E}$ 가 가공 및 저장 중 산화 등으로 인한 손실될 것으로 보여진 다. 전반적으로 본 연구에서 분석한 7종 수산가공품의 비타 민 $\mathrm{E}$ 함량 수준이 생것에 비하여 비교적 높게 나타나 생것으 로 유통되는 수산자원뿐만 아니라 수산가공품을 통해서도 상 당량의 비타민 $\mathrm{E}$ 를 섭취할 수 있을 것으로 생각된다.

한편, '2020 한국인 영양소 섭취기준’에 따르면 성인 기준 비타민 $\mathrm{E}$ 의 충분섭취량은 $12 \mathrm{mg} \alpha$-TE이며 상한섭취량은 $540 \mathrm{mg} \alpha$-TE로 알려져 있다(KDRIs, 2020). 본 연구에서 분 석한 20 종의 수산물 및 수산가공품의 경우 $100 \mathrm{~g}$ 섭취 기준 
으로 일일기준 최대 $5 \%$ 수준까지 비타민 $\mathrm{E}$ 를 섭취할 수 있 을 것으로 보여지며 다빈도 섭취를 고려해 볼 때 이들의 충족 량은 더 증가할 것으로 보여진다.

\section{분석품질 및 분석숙련도 평가}

비타민 $\mathrm{A}$ 와 $\mathrm{E}$ 의 분석품질관리는 $\mathrm{QC} \operatorname{chart(Fig.~1)ㄹㅡㄹ~ㅈㅏㄱㅅㅓㅇ~}$ 하여 관리하였다. QC chart는 분석 기간 동안 검증된 분석법 으로 분석 시 내부 및 외부 변동 요인에 의해 문제가 없는지 에 대한 분석의 품질을 관리하며, 다양한 변수에 의해 영향을 받는 분석 결과를 관찰할 수 있다(Moon 등, 2019). Fig. 1에 나타난 QC chart의 분석값은 분석 시 동시에 진행하였으며, 분석값이 UCL과 LCL 범위 밖으로 벗어나는 경우, 분석 조 건과 환경 등을 재점검하고 분석된 시료를 재분석하여 결과 값을 비교하였다. 레티놀 1회, 베타카로틴 3 회, $\gamma$-T 1회를 제 외한 모든 분석성분은 관리 범위 내에 들어오는 것을 확인하 였으며, $\gamma$-T의 경우 분석 조건을 점검하여 데이터로 사용하 였다. 이는 본 연구에서 진행된 비타민 $\mathrm{A}$ 와 $\mathrm{E}$ 분석이 모두 수용 가능한 분석 환경에서 진행되었음을 보여주며, 본 연구 에서 얻어진 지용성 성분에 대한 분석값은 수산물 및 수산가 공품의 데이터베이스로 활용할 수 있는 신뢰도를 나타냈다.

분석숙련도 평가를 위해 국제숙련도시험 PT-21124에 참 여한 결과, 레티놀 분석에 대한 z-score는 $-0.1, \alpha-\mathrm{T}$ 분석에

(a)

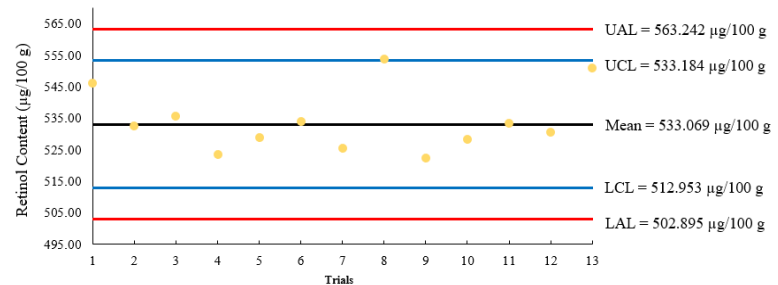

(b)

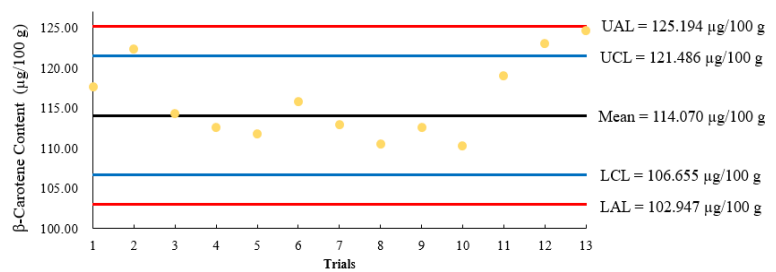

(c)

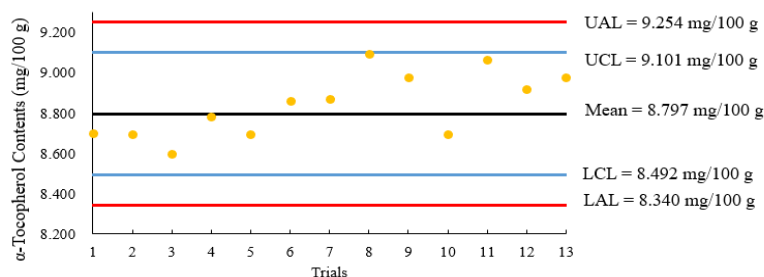

대한 z-score 값은 -1.1로 나타냈다(Table 8). z-Score는 표준 편차를 단위로 하여 측정값이 평균에서 벗어난 정도를 평가 하는 것으로, 일반적으로 \pm 2 이내의 범위에 들어오는 경우 국제적으로 우수한 분석숙련도를 보유하고 있음을 나타낸다. 본 연구에서 참여한 FAPAS 시험에서의 z-score는 비타민 A 와 $\mathrm{E}$ 분석 모두 \pm 2 이내의 값을 나타내어 검증된 분석법을 이용한 분석을 수행하는 숙련도가 국제적인 수준으로 우수함 을 보여준다 하겠다.

\section{요 약}

본 연구에서는 국내에서 소비되는 수산물 및 수산가공품 중의 비타민 $\mathrm{A}$ 와 $\mathrm{E}$ 프로파일에 대한 신뢰도 높은 국가식품 성분 데이터베이스 구축을 위해 총 10 종의 vitamer 분석에 대한 분석법 검증과 함께 수산자원 시료 분석에 대한 분석품 질관리 및 숙련도 시험 검증을 수행하였다. 총 20종 수산식품 중의 비타민 $\mathrm{A}$ 와 $\mathrm{E}$ 함량은 saponification-HPLC/PDA/FLD 로 분석하였으며, 직선성, 검출한계, 정량한계, 정밀성, 정확성, in-house 분석품질관리 및 국제 분석숙련도 평가를 수행하였 다. 레티놀, 베타카로틴 and $\alpha-\mathrm{T}$ 분석 검출한계는 각각 0.380 $\mu \mathrm{g} / 100 \mathrm{~g}, 0.602 \mu \mathrm{g} / 100 \mathrm{~g}, 0.0002 \mathrm{mg} / 100 \mathrm{~g}$ 으로 나타나 민 감도가 높은 분석법으로 수산자원의 비타민 $\mathrm{A}$ 와 $\mathrm{E}$ vitamers

(d)

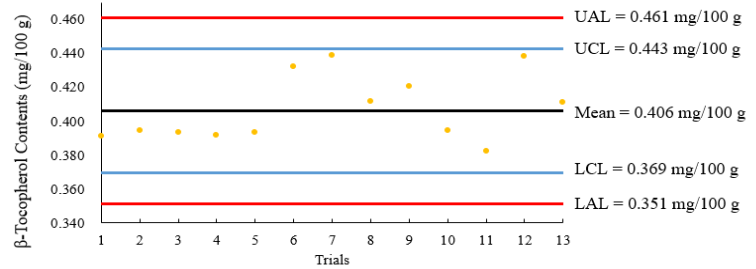

(e)

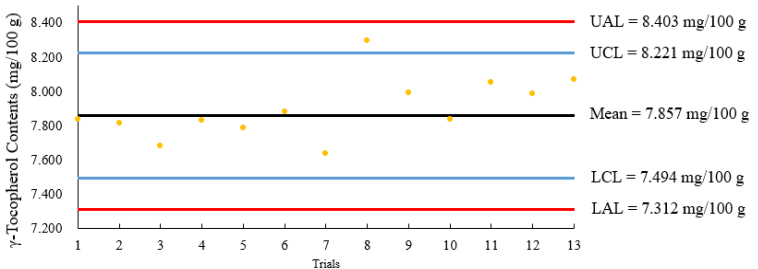

(f)

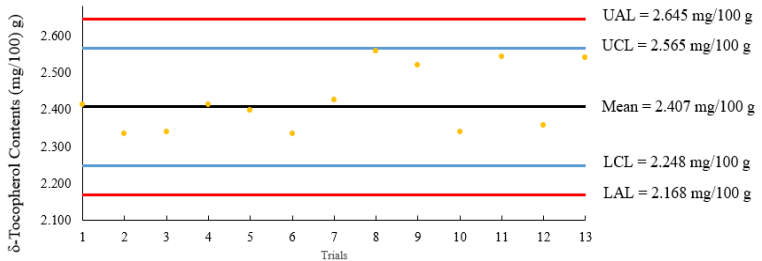

Fig 1. Quality control charts of retinol, $\beta$-carotene and tocopherols.

(a), Retinol; (b), $\beta$-Carotene; (c), $\alpha$-Tocopherol; (d), $\beta$-Tocopherol; (e), $\gamma$-Tocopherol; (f), $\delta$-Tocopherol. 
Table 8. z-Scores of retinol and $\alpha$-tocopherol analyses in a proficiency test (Food Analysis Performance Assessment Scheme, FAPAS)

\begin{tabular}{|c|c|c|c|c|}
\hline Analytes & Test sample name & Assigned value & Analytical value & z-Score \\
\hline Vitamin $A^{1)}(\mu \mathrm{g} / 100 \mathrm{~g})$ & \multirow{2}{*}{ Powdered baby food } & 492.0 & 483.94 & -0.1 \\
\hline Vitamin $E^{2)}(\mathrm{mg} / 100 \mathrm{~g})$ & & 11.4 & 10.17 & -1.1 \\
\hline
\end{tabular}

${ }^{1)}$ As retinol, the sum of cis- and trans-isomers

${ }^{2)}$ As $\alpha$-tocopherol

를 검출 및 정량 가능한 것으로 나타났다. 분석 정밀성(RSD $5 \%$ 이하)과 정확성(회수율 $90 \%$ 이상)도 비타민 $\mathrm{A}$ 와 $\mathrm{E}$ 에 대 하여 모두 우수한 것으로 나타났다. 총 20종의 수산물 및 수 산가공품의 비타민 $\mathrm{A}$ 는 0.00-311.77 $\mu \mathrm{g} \mathrm{RAE,} \mathrm{비타민} \mathrm{E}$ 는 0.01-0.62 mg $\alpha$-TE의 범위를 나타내 수산자원의 종류의 특 성에 따라 다양한 수준으로 존재하는 것으로 확인되었다. 식 물성 수산자원인 해조류에서 다량의 베타카로틴(538.16$689.84 \mu \mathrm{g} / 100 \mathrm{~g}$ )이 검출되었으며 동물성 수산자원에서도 내 장을 이용하는 패류(피조개 $27.17 \mu \mathrm{g} / 100 \mathrm{~g}$, 진주담치 29.30 $\mu \mathrm{g} / 100 \mathrm{~g}$, 참소라 $335.05 \mu \mathrm{g} / 100 \mathrm{~g}$ )와 일부 갑각류(꽃게 $186.53 \mu \mathrm{g} / 100 \mathrm{~g}$ )에서 높은 수준의 베타카로틴 함량이 검출 되었다. 비타민 $\mathrm{E}$ 는 모든 수산 시료에서 검출되었으며, 명란 젓과 같은 가공품은 첨가되는 고춧가루에 의해 20 개 수산식 품 중에서 비타민 $\mathrm{A}$ 와 $\mathrm{E}$ 모두 가장 높은 함량을 나타냈다. 본 연구에서 분석한 수산물 및 수산가공품의 비타민 $\mathrm{A}$ 와 $\mathrm{E}$ 의 프로파일을 볼 때 생것과 가공품 모두 지용성 비타민 $\mathrm{A}$ 와 $\mathrm{E}$ 의 좋은 급원식품이 될 수 있을 것으로 사료된다. 본 연구의 모든 과정 중 분석품질관리를 수행하여 모든 시료 분석 결과 가 신뢰도 높게 수행되었음이 확인되었으며 국제분석숙련도 에서도 본 연구의 분석수행이 숙련도와 정확성이 우수한 것으 로 확인되었다. 본 연구는 국내 다소비되는 수산물 및 수산가 공품의 비타민 $\mathrm{A}$ 와 $\mathrm{E}$ 프로파일에 대한 정보를 제공하며 이는 국가성분 데이터베이스로 활용될 수 있을 것으로 보인다.

\section{감사의 글}

이 논문은 2021년도 국립수산과학원 수산시험연구사업 (R2021061)의 지원으로 수행된 연구입니다.

\section{Conflict of interests}

The authors declare no potential conflict of interest.

\section{ORCID}

Ye-Eun Park

https://orcid.org/0000-0003-3936-0452

Jiyeon Chun

https://orcid.org/0000-0002-0093-0203

\section{References}

AOAC. AOAC Guidelines for Single Labrtatory Validation of Chemical Methods for Dietary Supplements and Baotanicals. Association of Official Analytical Chemists, Gaithersburg, MD, USA, p 12-13 (2002a)

AOAC. AOAC Guidelines for Single Labrtatory Validation of Chemical Methods for Dietary Supplements and Baotanicals. Association of Official Analytical Chemists, Gaithersburg, MD, USA, p 22 (2002b)

Bae HJ, Jun MR, Kim YG. Study on the vitamin contents of commercial powdered infant formula. J Life Sci, 17, 1689-1694 (2007)

Ball GFM. Vitamins in Foods-Analysis, Bioavailability and Stability. Taylor \& Francis, London, UK, p 3 (2005)

Chun A, Lee YY, Kim DJ, Yoon MR, Oh SK, Choi IS, Hong HC. Cultival comparision on tocopherols, tocotrienols, and antioxidant compounds in rice bran. Korean J Crop Sci, 58, 367-375 (2013)

Dominguez R, Barba FJ, Centeno JA, Putnik P, Alpas H, Lorenzo JM. Simple and rapid method for the sinultaneous determination of cholesterol and retinol in meat using normal-phase HPLC technique. Food Anal Methods, 11, 319-326 (2018)

Dror DK, Allen LH. Vitamin E deficiency in developing countries. Food Nutr Bull, 32, 124-143 (2011)

Gornas P, Siger A, Czubinski J, Dwiecki K, Seglina D, Kalucka MN. An alternatice RP-HPLC method for the separation and determination of tocopherol and tocotrienol homologues as butter authenticity markers: A comparative study between two European countries. Eur J Lipid Sci Technol, 116, 895-903 (2014)

Han YH, Seo JH, Shin GR, Shin JY, Jo YY, Hyun TS. Nutrient composition and content of vitamin and mineral supplements and their approproateness for pregnant and lactating women in Korea. Korean J Community Nutr, 23, 341-351 (2018) 
Hwang GJ. Elderly people and vitamins. J Kor Soc HealthSyst Pharm, 19, 147-152 (2002)

Hwang KM, Bae JW, Hu SJ, Oh KS. Determination of $\beta$ carotene in infant formulas by high-performance liquid chromatography. J Food Hyg Saf, 34, 334-339 (2019)

Karnjanqwipagul P, Nittayanuntawech W, Rojsanga P, Suntornsuk L. Analysis of $\beta$-carotene in carrot by spectrophotometry. Mahidol University J Pharm Sci, 37, 8-16 (2010)

Kim DS, Lee JH, Kim SG, Lee DU, Park SJ, Lee JH, Lee KP, Choi SW, Baik MY. Effects of temperature and relative humidity on far soluble vitamin contents in commercial vitamin tablet. J Korean Soc Appl Biol Chem, 49, 103-107 (2006)

Kim HJ, Lee SG, Park JJ, Kim HJ. Analysis of vitamin E and $\mathrm{K}$ contents in sea algae and vegetables frequently consumed in Korea for national standard food composition database. Korean J Food Sci Technol, 53, 19-28 (2021)

Korea Food and Drug Administration (KFDA). Korean Food Standard Codex. Korea Food Drug Administration. Chungju, Korea, p 131-137 (2017)

Lee GI, Kim SY. Analysis of the consumption structure of fishery products. J Rural Develop, 26, 21-38 (2003)

Ministry of Health and Welfare, The Korean Nutrition Society. Dietary Reference Intakes for Koreans. Sejong, Korea, p 11-14 (2020a)

Ministry of Health and Welfare, The Korean Nutrition Society. Dietary Reference Intakes for Koreans. Sejong, Korea, p 92-93 (2020b)

Mok JS, Lee DS, Yoon HD, Park HY, Kim YK, Wi CH.
Proximate composition and nutritional evaluation of fisheries products from the Korean coast. J Kor Fish Soc, 40, 259-268 (2007)

Moon HG, Islam MA, Chun JY. Analysis of retinol, $\beta$ carotene, vitamin $\mathrm{E}$ and cholesterol contents in steamed and braised dishes of the Korean diet. Korean J Food Preserv, 26, 796-807 (2019)

National Institute of Fishieries Science (NIFS). Composition Table Marine Products in Korea. $8^{\text {th }}$ ed, National Institute of Fisheries Science, Busan, Korea, p 1-394 (2018)

Park SH, Song WJ, Chun JY. Analyses of cholesterol, retinol, $\beta$-catorene and vitamin $\mathrm{E}$ contents in regional food of South Korea. J Korean Soc Food Sci Nutr, 47, 429-439 (2018)

Semba RD. Vitamin A, infection and immune function. In: Nutrition and Immune Function, Calder PC, Field CJ, Gill HS (Editor), CABI, New York, USA, p 151-169 (2002)

Sommer A. Vitamin A deficiency and clinical deisease: An historical overview. J Nutr, 138, 1835-1839 (2008)

Tang G. Bioconversion of dietary provitamin A carotenoids to vitamin A in humans. Am J Clin Nutr, 73, 1468-1473 (2010)

Thomas JB, Kline MC, Gill LM, Yen JH, Duewer DL, Sniegoski LT, Sharpless KE. Preparation and value assingment of standard reference material 968c fat-soluble citamins, carotenoids and cholesterol in human serum. Clin Chin Acta, 305, 141-155 (2001) 